This item was submitted to Loughborough's Research Repository by the author.

Items in Figshare are protected by copyright, with all rights reserved, unless otherwise indicated.

\title{
Orientationally textured thin films of WOx deposited by pulsed laser deposition
}

PLEASE CITE THE PUBLISHED VERSION

http://dx.doi.org/10.1088/2053-1591/1/4/046408

\section{PUBLISHER}

(C) Institute of Physics

\section{VERSION}

AM (Accepted Manuscript)

\section{PUBLISHER STATEMENT}

This work is made available according to the conditions of the Creative Commons Attribution-NonCommercialNoDerivatives 4.0 International (CC BY-NC-ND 4.0) licence. Full details of this licence are available at: https://creativecommons.org/licenses/by-nc-nd/4.0/

\section{LICENCE}

CC BY-NC-ND 4.0

\section{REPOSITORY RECORD}

Caruana, Andrew J., and Michael D. Cropper. 2019. "Orientationally Textured Thin Films of Wox Deposited by Pulsed Laser Deposition”. figshare. https://hdl.handle.net/2134/16458. 


\title{
Orientationally textured thin films of $\mathrm{WO}_{\mathrm{x}}$ deposited by pulsed laser deposition
}

\author{
A J Caruana, M D Cropper ${ }^{\dagger}$
}

Department of Physics, Loughborough University, Loughborough, LE11 3TU, UK

Email: m.d.cropper@lboro.ac.uk

${ }^{\dagger}$ To whom correspondence should be addressed.

\section{Short Title: PLD of WOx}

\section{PACS:}

\subsection{5.cp X-ray diffraction}

68.55.-a Thin film structure and morphology

\subsection{J- Morphology of films}

\subsection{5.jm Texture}

\subsection{Fg Pulsed laser ablation deposition}

\subsection{Hk Scanning electron microscopy (SEM) (including EBIC)}

\begin{abstract}
Pulsed laser deposition from a compound target in an oxygen atmosphere has been used to produce sub-stoichiometric $\mathrm{WO}_{\mathrm{x}}$ films of $30 \mathrm{~nm}$ thickness on $\mathrm{Si}(100)$ and $\mathrm{SrTiO}_{3}(100)$ substrates. The growth temperature was $500^{\circ} \mathrm{C}$ and the pressure of the $\mathrm{O}_{2}$ background was $2.5 \times 10^{-2}$ mbar. The films have been assessed using X-ray photoelectron spectroscopy, X-ray reflectivity, X-ray diffraction and scanning electron microscopy. The chemical shift of the tungsten $4 \mathrm{f}$ states showed that the tungsten was close to fully oxidised. X-ray reflectivity measurements and scanning electron micrographs showed the films on $\mathrm{SrTiO}_{3}(100)$ to be much smoother than those on $\mathrm{Si}(100)$ which were granular. X-ray diffraction in the BraggBrentano geometry combined with texture analysis showed that the films were textured with the [001], [010], [100] directions normal to the surface. The films on $\mathrm{SrTiO}_{3}(100)$ were found to be biaxially textured with the film directions aligning with those in the substrate. The nature of the texture was sensitive to the laser fluence used. Higher fluence promoted [001] texture whereas lower fluence promoted [010] and [100]. Intermediate fluences produced smooth, highly ordered films with biaxial texture. Investigations using the laser repetition rate indicate that the mechanism for the difference is the overall deposition rate, which is affected by fluence. On $\mathrm{Si}(100)$ the films were rougher and exhibited only uniaxial texture.
\end{abstract}




\section{Introduction}

Stoichiometric $\mathrm{WO}_{3}$ is an n-type wide-band-gap semiconducting oxide. The band gap in thin film $\mathrm{WO}_{3}$, however, is dependent on the grain structure; increasing the crystallite size decreases the band gap. Consequently adjusting the deposition parameters can tune absorption properties, and so thin film $\mathrm{WO}_{3}$ is transparent to the majority of the visible light spectrum. $\mathrm{WO}_{3}$ is also electro-chromic and gas-chromic so the visible colour of $\mathrm{WO}_{3}$ thin films can be reversibly changed. These properties have made thin film $\mathrm{WO}_{3}$ the focus of various applications studies such as: thin film gas sensors [1], electro-chromic devices [2] and solar cell production $[3,4]$.

Given its potential technological importance, there have been several reports of the production of thin films of the material by various physical vapour deposition methods, including evaporation and magnetron sputter deposition. Pulsed laser deposition (PLD) is known to be an important method for the deposition of oxide materials [5], but there have been relatively fewer investigations of its utility in the deposition of $\mathrm{WO}_{3}$ and substoichiometric $\mathrm{WO}_{\mathrm{x}}$

Following deposition using PLD from a $\mathrm{WO}_{3}$ target using $308 \mathrm{~nm}$ radiation the microstructure and subsequent electrical properties of $\mathrm{WO}_{3}$ thin films have been investigated [6, 7], in particular the influence of substrate temperature and oxygen pressure. The films were deposited onto ITO coated glass and Si(111) substrates. Increasing oxygen background pressure during deposition was found to raise the resistance of the film; an atmosphere of $7 \mathrm{~Pa}$ of $\mathrm{O}_{2}$ gave films that were conducting, $10 \mathrm{~Pa}$ semiconducting, and $15 \mathrm{~Pa}$ highly resistive [6]. The oxygen deficiency induced by low pressures results in greater conduction between tungsten atoms. Pressure also influenced microstructure: at lower pressures the films were found to be amorphous, but for $\mathrm{O}_{2}$ pressures between 15 and 20 Pa they became polycrystalline. In the second study [7] $\mathrm{WO}_{3}$ was deposited onto $\mathrm{Si}(111)$ at $200^{\circ} \mathrm{C}$ and postdeposition annealing was used which again converted the films from amorphous into polycrystalline.

The influence of substrate temperature on the microstructure of thin films deposited onto glass substrates by PLD using $532 \mathrm{~nm}$ radiation has also been investigated [8]. Three films were deposited at substrate temperatures of $300 \mathrm{~K}, 523 \mathrm{~K}$ and $673 \mathrm{~K}$ from a $\mathrm{WO}_{3}$ target within an oxygen background. Films deposited at $300 \mathrm{~K}$ were found to be translucent, but deposition at $523 \mathrm{~K}$ and $673 \mathrm{~K}$ resulted in transparency. All conditions gave triclinic contributions but films were predominantly orthorhombic in structure, exhibiting preferred orientation texture of [001]. The grain size and surface roughness was found to decrease with 
increasing substrate temperatures. At $300 \mathrm{~K}$ the film exhibited porous gaps at the crystallite grain boundaries but these decreased in size at the higher deposition temperatures.

There have been few studies of epitaxial growth of $\mathrm{WO}_{3}$ on $\mathrm{SrTiO}_{3}(100)$. The influence of substrate temperature on the epitaxy of magnetron sputtered $\mathrm{WO}_{3}$ thin films grown on $\mathrm{SrTiO}_{3}$ substrates has been studied [9]; it was observed that at all substrate temperatures in the range $500^{\circ} \mathrm{C}$ to $850^{\circ} \mathrm{C}$ the films exhibited strong preferential [001] texture and that substrate temperatures higher than $500^{\circ} \mathrm{C}$ gave a secondary [020] texture, the degree of which was dependent on the substrate temperature. Pole figure analysis of the [222] $\mathrm{WO}_{3}$ lattice reflection demonstrated four-fold symmetry, which confirmed [001] epitaxy. Further pole figure analysis of the [112] $\mathrm{WO}_{3}$ lattice reflection allowed the degree of epitaxy to be quantified. The four-fold symmetry was observed but additional poles were present in films grown at substrate temperatures higher than $500^{\circ} \mathrm{C}$. This indicated that additional orientations were present within these films and that the greatest degree of epitaxy occurred at $500^{\circ} \mathrm{C}$.

As part of a larger growth study of $\mathrm{WO}_{3}$ on glass [10] the influence of background $\mathrm{O}_{2}$ pressure on the growth of epitaxial $\mathrm{WO}_{3}$ on $\mathrm{SrTiO}_{3}$ substrates by PLD using $\mathrm{WO}_{3}$ target and $248 \mathrm{~nm}$ radiation has been reported. The films investigated were grown at $600^{\circ} \mathrm{C}$ and were found to texture predominantly in the [002] $\mathrm{WO}_{3}$ lattice reflection, but were found to have a contribution from the [020] lattice reflection - the strength of which appeared to reduce with increasing $\mathrm{O}_{2}$ deposition pressure. The contribution from the [020] lattice reflection was almost fully suppressed at $\mathrm{O}_{2}$ pressures above 150 mTorr, indicating improved epitaxy with respect to films deposited at lower pressures.

The effect of laser fluence is known to have subtle effects on the structure and microstructure of thin films grown by PLD [11] through changes in the instantaneous deposition rate, overall rate, or energy of deposited species, but as yet little work has been done in this area for the case of $\mathrm{WO}_{3}$. A preliminary work (as part of a larger investigation) on the effect of laser fluence on the surface morphology of $\mathrm{WO}_{3}$ thin films has been reported [12]. In this investigation films were deposited from a metal tungsten target using RF assisted PLD. The films grown for the purpose of fluence comparison were deposited at $400^{\circ} \mathrm{C}$ on Corning glass substrates. With reducing fluence, the morphology was found to become smoother and more compact with a reduction in droplet density. No investigation of orientation texture was reported.

In this manuscript we report an investigation into the growth of sub-stoichiometric $\mathrm{WO}_{\mathrm{x}}$ thin films on both $\mathrm{Si}(100)$ and $\mathrm{SrTiO}_{3}(100)$ substrates using PLD. The study focusses on the crystallinity and microstructure of the film and the effect of varying fluence. We show that 
films may be produced with distinct biaxial texture and that the precise value of the fluence has an important effect on film properties.

\section{Experimental}

The experimental work was carried out in the laboratories of Loughborough University. An ultrahigh vacuum system was used to deposit the films onto single crystal substrates using visible light of various fluences. The resulting thin films were analysed for crystal structure, microstructure and composition using X-ray diffraction and spectroscopy, and electron imaging methods.

The PLD system used for this work [13] was constructed by Cryogenic and Vacuum Technology Ltd and incorporates a PLD process designed by the IWS Dresden [14]. The vacuum hardware is a three chamber MBE type UHV with a base pressure of $2 \times 10^{-10} \mathrm{mbar}$ after bake-out. The deposition chamber is a double-skinned, water-cooled domed cylinder with ion and titanium sublimation pumps. It may also be pumped by a turbomolecular and mechanical pump combination during rough pumping or when reactive gases are to be used. The targets are mounted horizontally in the base of the chamber and may be translated, rotated and changed under stepper-motor control. The substrate is mounted vertically above the targets at a distance of $110 \mathrm{~mm}$ and may be heated using a silicon carbide wander track controlled by a thermocouple that is behind the heater at a similar distance as the substrate. The calibration of the substrate temperature has been verified previously using another thermocouple attached to the substrate platen.

The PLD system is equipped with a $10 \mathrm{~W}$ pulsed Nd:YAG laser manufactured by Quanta Ray. The pulse repetition rate is $10 \mathrm{~Hz}$ and the power of each pulse may be controlled by a Qswitch. The laser is equipped with non-linear optics to frequency double the infra-red fundamental into the visible at $532 \mathrm{~nm}$. Further frequency selection is achieved by two wavelength selective thin-film mirrors and a lens is used to focus the beam into the chamber through a fused silica viewport.

The film deposition employed oxide targets of stoichiometric $\mathrm{WO}_{3}$ manufactured to $99.95 \%$ purity and supplied by Pi-Kem Ltd. The films were deposited onto two different substrates: polished and pre-diced $\mathrm{Si}(100) 10 \times 10 \mathrm{~mm}$ wafer segments and polished $\mathrm{SrTiO}_{3}(100)$ of the same size. The substrates were cleaned ex situ using acetone. For the silicon substrates this involved immersion for three minutes to remove the protective film, a rinse in clean acetone and then immediate insertion into the load-lock. $\mathrm{SrTiO}_{3}$ substrates received only the rinse. The substrates were baked under high vacuum in the load-lock at $120^{\circ} \mathrm{C}$ for four hours before 
transfer into the deposition chamber. Prior to deposition, the substrates underwent further outgassing at the deposition temperature until the chamber pressure had fallen to $2 \times 10^{-8}$ mbar.

The thin films were deposited in an oxygen pressure of $2.5 \times 10^{-2}$ mbar of oxygen (99.9995\% BOC) which was continuously replenished using a combination of leak valve and baffled turbomolecular pump to maintain flow. This pressure was selected to give slightly substoichiometric films but so that fully stoichiometric films could be produced by slight increase in pressure, thus putting the experiment in the region where control is possible. This choice was influenced by previous reports $[10,15]$ and our preliminary experiments at different oxygen pressures. The temperature during deposition was $500^{\circ} \mathrm{C}$, a temperature that was found to produce good crystalline structure. This was again selected following some preliminary experiments, and is consistent with growth temperatures used in deposition by other techniques [8]. Directly after deposition the substrates were allowed to cool immediately down to $50^{\circ} \mathrm{C}$ in the oxygen environment.

The films were deposited at five different fluences, namely 5.3, 7.6, 10.1, 12.4 and $14.7 \mathrm{~J} \mathrm{~cm}^{-}$ ${ }^{2}$, which had previously been determined using a laser power meter and measurement of crater size from one shot and ten. Following preliminary experiments, the number of pulses employed was adjusted to give film thickness $30 \mathrm{~nm}$ for each fluence. The mean deposition rates for $\mathrm{SrTiO}_{3}$ substrates for these fluences were 0.73, 1.09, 1.45, 1.74 and $2.49 \mathrm{~nm} \mathrm{~min}^{-1}$ respectively. This film thickness was determined by grazing incidence $\mathrm{X}$-ray reflectivity (XRR) described below. Investigating the effect of laser fluence on film structure requires some caution: the fluence can modify the target surface, which in turn affects growth [16]. Each nominal fluence was allocated to a different region of the target and the fresh surface of the target was pre-conditioned using the same fluence before any deposition. In this way the target surface was in the steady state condition achieved by each fluence before deposition commenced.

The films were analysed ex situ by various forms of X-ray diffraction (XRD), by electron microscopy and by X-ray photoelectron spectroscopy (XPS). Structural analysis was performed using XRD in the Bragg-Brentano $\theta-2 \theta$ geometry symmetrically about the surface normal utilising a Bruker D2 Phaser and the filtered $\mathrm{Cu} \mathrm{K}_{\alpha}$ line at $0.154 \mathrm{~nm}$. Pole figure of selected films were collected in the reflection geometry employing the [220] and [112] reflections of $\mathrm{WO}_{3}$; the former to investigate four-fold symmetry and the latter to determine the orientation and presence of [001], [010] and [100] textures. Measurement of pole figures was accomplished using a D8 diffractometer configured with the tube positioned in the point focus mode, a light tube collimator and a quarter-circle Eulerian cradle with three-axis 
translation. Scattered X-rays were detected using both graphite monochromated scintillation counter ([220] figures) and a Bruker Sol-X energy dispersive detector ([112] figures). Grazing incidence XRR curves were collected using the D8 and a specially modified D5000 to quantify film thickness The XRR data was modelled and fitted using the Bruker Leptos software package [17].

The microstructure of the films was imaged using a Leo 1530FE high resolution field emission gun scanning electron microscope (FEGSEM). This instrument has a primary energy of $5 \mathrm{keV}$ and was used at magnifications of $10^{5}$. Compositional profiles were obtained by XPS using a Thermo K Alpha with X-ray energy $1486.7 \mathrm{eV}$. All of the equipment is located in the laboratories of Loughborough University, the FEGSEM, D8 and XPS are operated by the Loughborough Materials Characterisation Centre and the remaining equipment is based in the Department of Physics.

\section{Results and Discussion}

\subsection{Film Composition and Thickness}

All of the films deposited here are optically flat and smooth and have no obvious colouration. We have performed analysis of the films using XPS and grazing incidence XRR. Figure 1(a) shows an XPS survey scan of a film deposited using $7.6 \mathrm{Jcm}^{-2}$ fluence onto $\mathrm{SrTiO}_{3}(100)$, which was typical of all the films and Figure 1(b) shows XRR scans of films deposited at the same power onto both substrates.

The XPS analysis, Figure 1(a), shows that the film comprises almost entirely oxygen and tungsten, with the tungsten being close to fully oxidised. The oxidation state of tungsten may be determined by the binding energy of the $4 \mathrm{f}$ electron states; the binding energy of the $4 f_{7 / 2}$ is $31.6 \mathrm{eV}$ in metal and $36.1 \mathrm{eV}$ in $\mathrm{WO}_{3}$, with a similar chemical shift in the $4 \mathrm{f}_{5 / 2}$ state $[18,19,20,21]$. The XPS spectra showed no evidence of any tungsten in the metallic state, and quantification of the survey scan using the Schofield sensitivity factors was consistent with a composition ratio close to 1:3.

It is not unusual for $\mathrm{WO}_{3}$ thin films to be prepared sub-stoichiometric [22], and the aim of this research was to aim for deposition conditions that would make films slightly substoichiometric but that could achieve full stoichiometry with small adjustment of the oxygen pressure. Detail of the photoemission from the tungsten $4 \mathrm{f}$ states is shown in the inset to Figure 1. It can be seen that the peaks are chemically shifted to the binding energy consistent with a +6 oxidation state. However a slight asymmetry is apparent on the low binding energy 
side of the $4 \mathrm{f}_{7 / 2}$ emission peak. This shoulder is consistent with a small fraction of the sampled tungsten being in the +5 oxidation state $[10,21]$ as desired. Fitted peaks are shown in the figure but as the sample was transferred ex situ, quantification is not appropriate.

XPS analysis of the sample revealed some contamination that was restricted to the very surface layer of the film: no contamination was found at the film-substrate interface or within the film. Surface contamination included carbon (18 at\%) which is common for surfaces analysed $e x$-situ, molybdenum (1 at\%), and sodium (0.6 at\%). A very short etch with an argon ion beam revealed that these elements were entirely confined to the surface layer. The molybdenum contamination probably occurred during sample transfer within the vacuum system. Aside from these three elements the only elements detectable by XPS were tungsten, oxygen and the substrate elements. Depth profiling of some metal oxides using XPS is problematic $[18,23]$, because the action of the argon ion beam causes the compound to disintegrate and the film enriches with the metallic element. However, comparison with a piece of $\mathrm{WO}_{3}$ target that was etched under the same conditions was also consistent with a film that was close to full oxidation.

Analysis using XRR indicates that all the films have thickness around $30 \mathrm{~nm}$, as intended. The thickness distribution for the films deposited onto $\mathrm{SrTiO}_{3}(100)$ was particularly narrow at 28-33 nm with no systematic variation across the fluence range. Roughness of surface and interface was in 1-1.5 nm for all films except the one deposited at highest fluence, which had roughness of $2 \mathrm{~nm}$. The scatter in these values for the lower fluence films probably reflects the accuracy of the determination rather than systematic variation. Inclusion of a carbon contamination layer in the model made only a marginal difference to the values. For the films deposited onto $\mathrm{Si}(100)$ the scatter in measured thickness and roughness was larger, being 27$37 \mathrm{~nm}$ and 3-4 nm respectively. This wider scatter in the determination of values probably reflects the poorer quality of the growth surface. A comparison between the XRR scans for films deposited on both substrates at $7.6 \mathrm{Jcm}^{-2}$ fluence is shown in Figure 1.

\section{$3.2 \quad \theta-2 \theta$ X-ray Diffraction}

The XRD collected in the $\theta-2 \theta$ geometry is a common method for determining the orientation texture of thin films. Figure 2 shows scans collected from five $\mathrm{WO}_{\mathrm{x}}$ films deposited onto $\mathrm{Si}(100)$ substrates. These scans are consistent with an approximately pseudocubic [001] predominant orientation texture as is demonstrated by the presence of the (002) or related lattice reflection for all the films: however, the detail differs. The scan at the bottom of the figure is from the polycrystalline $\mathrm{WO}_{3}$ target and is equivalent to powder diffraction. The 
triplet of reflections between $23^{\circ}$ and $24.5^{\circ}$ is characteristic of the stable monoclinic $\gamma-\mathrm{WO}_{3}$ phase [24]; the [002] reflection is at a $2 \theta$ angle of $23.117^{\circ}$, the [020] is at $23.583^{\circ}$, and the [200] at $24.387^{\circ}$. All three of these orders have similar structure factors. A higher temperature phase, orthorhombic $\beta-\mathrm{WO}_{3}$ [25], gives respective $2 \theta$ angles of $22.920^{\circ}, 23.485^{\circ}$ and $24.229^{\circ}$. These two phases are unlikely to be distinguished by XRD alone as thin films are typically strained. Given that the films may be slightly sub-stoichiometric as revealed by XPS, we need to consider XRD from these phases. X-ray analysis of monoclinic $\mathrm{WO}_{2.90}$ [26, 27] gives a series of six peaks of varying intensity between $20.6582^{\circ}$ and $24.4204^{\circ}$. We do not see evidence of all these peaks and again the phases would be difficult to distinguish in a strained film, so the structure of the films is probably most correctly described as a defected bulk phase of $\mathrm{WO}_{3}$. Certainly the pole plots presented later are consistent with this.

The first thing to notice is that the films are textured to a higher degree than many previous PLD studies of deposition onto glass or silicon substrates, exhibiting one predominant set of diffracted orders. This is most probably due to the growth temperature of $500^{\circ} \mathrm{C}$, which appears to be the best compromise in giving crystalline growth whilst retaining preferred texture. Our preliminary experiments indicated that $500^{\circ} \mathrm{C}$ was the minimum temperature required to produce the strongest diffracted orders, however higher temperatures offered no further improvement.

Looking first at the lowest fluence $5.3 \mathrm{~J} \mathrm{~cm}^{-2}$ film, shown in Figure 2(a), it can be seen that all three of the principal reflections, [002], [020] and [200] are present, but in different proportions than in a powder sample. This indicates that the preferred orientational texture of this film is [001], but that smaller amounts of [010] and [100] are present. The peaks are broader than for powder diffraction, suggesting smaller crystallite size which in this geometry is limited by the thickness of the film. The angular positions of the reflections correspond closely with those from the target, suggesting the film is not strained. The narrow reflection at $33.1^{\circ}$ is a weak order associated with the $\mathrm{Si}(100)$ substrate.

With increasing fluence, there are changes in the relative and absolute intensities of these reflections. Figure 2(a-e) shows the sequence of increasing fluence of 5.3, 7.6, 10.1, 12.4 and $14.7 \mathrm{~J} \mathrm{~cm}^{-2}$ respectively. Increased fluence results in an increase in the [001] orientational texture at the expense of the [010] and the [100]. There is also a variation in the [001] intensity suggesting that the overall degree of crystallinity varies. The small diffraction order at $47.2^{\circ}$ is the [004] reflection. 
Although the film deposited using a fluence of $7.6 \mathrm{~J} \mathrm{~cm}^{-2}$, Figure 2(b), shows the strongest [002] reflection it has shoulders corresponding to residual amounts of [020] and [200] orientations. These orders are less apparent at higher fluence, where the film is primarily [001] textured. Given that all the films have the same thickness and therefore the same sampling volume, the intensity of the [002] reflection can be associated with the degree of crystallinity. Variations in intensity may in principle be influenced by sample alignment in $\mathrm{XRD}$, but care was taken over this and the large mosaic structure typical of thin films means that the intensity is relatively insensitive to alignment. Thus it would appear that the highest degree of crystallinity is associated with intermediate fluences.

The $\theta-2 \theta$ scans for films deposited under similar conditions but onto $\mathrm{SrTiO}_{3}(100)$ substrates are shown in Figure 3. The behaviour here shows some similarities with the behaviour on $\mathrm{Si}(100)$ substrates, but also some important differences. The apparent crystallinity also maximises at low to medium fluence and high fluence again produces films that have a [001] preferred orientational texture. However, the angular position of the reflections at low fluence is very different. The detail of these scans is really quite different from those of films grown by magnetron sputtering [9] and shows a definite progression with fluence.

The $\theta-2 \theta$ scan from the lowest fluence of $5.3 \mathrm{~J} \mathrm{~cm}^{-2}$ is shown in Figure 3(a). The relative strength of the reflection is quite high and the angle of the main peak corresponds to an interplanar distance that is slightly larger than that of the [200]. Although the peak has asymmetry towards lower angle indicating that there is some mixture of reflections, it is clear that this data cannot be described as a simple mixture of [002], [020] and [200] in the same way that the equivalent film on $\mathrm{Si}(100)$ can be. Note that the strong reflection at $22.783^{\circ}$ arises from the substrate $\mathrm{SrTiO}_{3}[100]$ reflection and the second order of this can be seen at $46.535^{\circ}$.

With increasing fluence, the XRD changes markedly. The film deposited with fluence of 7.6 J $\mathrm{cm}^{-2}$, Figure 3(b), has a broad peak that appears to comprise a mixture of the [200], [020] and [002] reflections. By $10.1 \mathrm{~J} \mathrm{~cm}^{-2}$, Figure 3(c), the preferred orientation texture is [001], a picture that is repeated in the higher fluence films. By the highest fluence of $14.7 \mathrm{~J} \mathrm{~cm}^{-2}$ the film is almost entirely of [001] orientation but does not show a very strong reflection.

$\mathrm{SrTiO}_{3}(100)$ has a very close lattice match with $\mathrm{WO}_{3}$ : the lattice constant is $0.3905 \mathrm{~nm}$ which is about half the repeat unit of $\gamma-\mathrm{WO}_{3}$ and similar to the pseudo-cubic lattice constant. In the lowest fluence film, Figure 3(a), the strong reflection at $24.039^{\circ}$ requires some comment. This lies between and may be due to two equal [020] and [200] contributions with peak broadening 
due to small crystal size. If the peak is due to a single reflection then the angle of $24.039^{\circ}$ corresponds interplanar distance of $0.740 \mathrm{~nm}$. For $\gamma-\mathrm{WO}_{3}$, the interplanar distances for [001], [010] and [100] are 0.7692, 0.7540 and $0.7306 \mathrm{~nm}$ respectively [24], inviting the hypothesis that we have strained epitaxial matching to the [100]. Figure 3 also shows evidence of a second order reflection, visible at $49.169^{\circ}$. For $\beta-\mathrm{WO}_{3}$ these would be [004], [040] and [400] reflections visible at $46.828,48.037^{\circ}$ and $48.434^{\circ}$ respectively [25].

The possible reasons for the variation in texture with fluence require some consideration. There are at least three growth parameters that may be affected by fluence, including instantaneous deposition rate, mean deposition rate and the average energy of the incident species. All of these potentially influence the kinetics of the film formation on the growing surface and so affect the competition between deposition and diffusion that has a strong effect on nucleation and growth [28]. Additional energy in the deposited species may activate diffusion and film crystallisation processes, however a higher rate reduces the time available for these processes to take place.

The deposition of oxides usually requires the use of a reactive oxygen atmosphere that also affects the plume. Between about $1 \times 10^{-2} \mathrm{mbar}$ and $10 \times 10^{-2} \mathrm{mbar}$ is a transition region in which the plume forms a shock-front and is broadened, attenuated and decelerated [29, 30,31]. There is also the possibility of the formation of molecular complexes which will influence surface growth kinetics [29]. The pressure that we have selected is near the start of this transition region, so while there is significant deceleration the plume is not expected to fully thermalise [31] and the broadening will be small. A previous study on PLD of $\mathrm{WO}_{3}$ [10] found evidence of a $\mathrm{O}_{2}$ pressure dependence of the (010) to (100) transition at pressures several times higher than found here. At 150 mTorr (far higher than that used here) the films on $\mathrm{SrTiO}_{3}(100)$ still showed mixed texture and more than $200 \mathrm{mTorr}$ was required to induce a single (100) texture. This report and our experience of some preliminary experiments with pressure indicate that the influence of deceleration and attenuation by the background gas is not the principal mechanism for the texture change with fluence.

In addition to the deceleration by the background gas, the mean kinetic energy of the depositing species is also affected by the fluence [32]; increasing the fluence will increase the kinetic energy of the species alighting on the growing film, so increasing the activation of surface diffusion. However, there is evidence that the largest changes to kinetic energy occur at low fluences and increases in fluence in the intermediate region have a smaller relative effect [33]. The other effect of fluence is to increase the deposition rate, which acts in 
opposition to the kinetic energy in its effect on growth kinetics, giving less time for diffusion to occur.

To shed some light on the mechanism by which the fluence affects the film texture, we have deposited another film onto $\mathrm{SrTiO}_{3}(100)$ using a lower laser repetition rate of $5 \mathrm{~Hz}$ for comparison. This film was deposited using the intermediate fluence of $10.1 \mathrm{~J} \mathrm{~cm}^{-2}$ and all other parameters were kept the same. A comparison of the $\theta-2 \theta$ scans for this film is shown in Figure 4 compared with the $10 \mathrm{~Hz}$ film, where it can clearly be seen that the pulse rate affects the texture. In this comparison, the only parameter that will have been affected is the mean deposition rate, as pulse fluence is the same, both instantaneous deposition rate and the mean energy of the depositing species is the same.

As can be seen from figure 4, the film grown with the lower mean deposition rate exhibits both (001) and (010) orientational textures, whereas the higher rate favours (001) - as does higher fluence. This indicates that the mechanism for fluence affecting orientational texture is related to mean deposition rate. This suggests that the most commonly observed (001) texture is produced by kinetic limitations on surface diffusion and the other orientations are favoured by shifting the balance between deposition and diffusion towards greater diffusion. This conclusion would be consistent with very high $\mathrm{O}_{2}$ pressures favouring (001) texture [10] as deceleration of the plume would reduce the energy available to activate diffusion. This would indicate that the (001) orientation is a metastable phase promoted by kinetic limitations and that the other orientations occur when a relatively lower deposition rate enables diffusion to dominate.

In common with all deposition techniques, PLD creates a supersaturation at the substrate surface. However, the supersaturation induced by PLD is instantaneously many times that produced by other physical vapour deposition methods reducing the critical size of nucleations at the surface and increasing dramatically the nucleation density. This phenomenon is the reason why PLD can deposit smooth, epitaxial films at relatively low substrate temperature. The high nucleation density when combined with a high deposition rate can promote the stabilisation of metastable structures by depositing material at a higher rate than the rate of surface diffusion which enables the film to relax. This mechanism also promotes better microstructure such as surface smoothness [34] by enabling better filling of condensed layers prior to the nucleation of the next layer.

However, depositing at lower overall rates by reducing fluence or repetition rate can provide time for surface diffusion to enable the film to relax into a better matched or otherwise more 
optimal epitaxial structure. This process is also controlled by surface mobility promoted by use of a suitable substrate temperature and by the energy delivered to the growing film by the depositing species. The variation of structure with fluence that we report here is reminiscent of the variation of lattice parameter and surface morphology that has been reported in the deposition of other oxide materials [35, 36, 37]. Hence, as found here, adjustment of the laser fluence and repetition rate can be used to promote better epitaxial growth.

\subsection{Texture Analysis using Pole Figures}

To investigate the orientational texture of the films further, we have collected pole figures of all the films using both the [220] and [122] reflections of $\mathrm{WO}_{3}$. These are illustrated in Figures 5 to 7 . Figure 5 shows the (220) pole figures for $\mathrm{WO}_{\mathrm{x}}$ films deposited onto $\mathrm{Si}(100)$ for the series of fluences low (a) to high (e). It can be seen that these measurements when taken in combination with $\theta-2 \theta$ scans are consistent with a fibre texture. There is a tendency for the crystallites to order with the (001) direction normal to the substrate, but there is no preferred in-plane orientation. The degree of this out-of-plane alignment is strongest for the film deposited using a fluence of $7.6 \mathrm{Jcm}^{-2}$, illustrated in Figure 5(b).

The pole figures for the (220) reflections for the films deposited onto $\mathrm{SrTiO}_{3}(100)$ are shown in order of increasing fluence in Figure 6(a-e), and the pole figure for the (110) reflection of a $\mathrm{SrTiO}_{3}(100)$ substrate is shown in Figure 6(f) for comparison. Inspection of the figures reveals that in all cases the films are biaxially textured; that is there are preferred in-plane and out-of-plane orientations. This is evidenced by the four-fold symmetry, which would be consistent with an epitaxial texture.

In a previous work on sputter-deposited films [9], the orientation of $\mathrm{WO}_{3}$ films was investigated using (112) pole figures which can distinguish between the similar (002), (020) and (200) orientations. We have determined the (112) pole figures for our films deposited onto the single crystal substrate, $\mathrm{SrTiO}_{3}(100)$, which are illustrated in Figure 7(a-e) in order of increasing fluence. The (112) pole figure from the substrate is shown in Figure 7(f) for comparison. The pole figure for the substrate is consistent with a cubic system: there are twelve reflections, four in an inner ring and eight in an outer ring. For $\mathrm{WO}_{3}$, which is distorted from cubic, these reflections are non-equivalent. The four inner reflections indicate (001) orientation normal to the substrate and the two pairs of four outer reflections indicate (010) and (100) orientations. The probable existence of domains with two rotational orientations within the film means that the outer reflections will be symmetric regardless of preferred orientation between (010) and (100). 
Looking at the fluence series of $\mathrm{WO}_{\mathrm{x}}$ films in Figure 7 it can be seen that there is a systematic progression in the strength of the orders. For the film deposited at the lowest fluence of $5.3 \mathrm{~J}$ $\mathrm{cm}^{-2}$ Figure 7(a), the reflections indicating (010) and (100) orientations are strongest but the pole figure of the film deposited using the highest fluence of $14.7 \mathrm{~J} \mathrm{~cm}^{-2}$, Figure $7(\mathrm{e})$ is dominated by the (001) related reflection. This behaviour is consistent with the observations made in the $\theta-2 \theta$ geometry: the higher angle peak seen in the low fluence film, Figure 3(a), is consistent with (200) preferred orientation, whereas the peak position for the higher fluence film, Figure 3(e) is consistent with a (001) texture.

Note that pole figures collected from biaxially textured two-fold rotationally symmetric films on a four-fold rotationally symmetric substrate will not exhibit any variation between the reflections related to (010) or (100) oriented films due to the formation of domains with $90^{\circ}$ relative azimuthal rotation. Thus it is not possible to distinguish equal quantities of the two orientations from a single strained tetragonal structure in the case of Figure 7(a).

So to summarise, the combination of $\theta-2 \theta$ scans and pole plots reveals that low laser fluence favours the formation of (100) or (010) oriented biaxially textured films, but using a higher fluence changes this to (001) orientation. Note that in all cases the in-plane principal pseudocubic directions in the film are parallel with similar cubic directions in the substrate. The low power preferred orientation (100) puts the two larger lattice parameters of the $\mathrm{WO}_{\mathrm{x}}$ in-plane, which will ensure better matching with the larger substrate net. However, use of higher power produces films that match less well. This interpretation is consistent with the conclusion that the mechanism for the texture effect of fluence is related to the increased deposition rate.

\subsection{Scanning Electron Microscopy}

Scanning electron micrographs collected from the films are shown in Figures 8 and 9. Figure 8 shows those for films deposited onto $\mathrm{Si}(100)$ with 8(a) being the lowest fluence and 8(e) the highest. It can be seen that the typical grain size is around $20 \mathrm{~nm}$ and that there are no preferred azimuthal orientations to the crystallites. There is also a tendency to smaller grains with increasing fluence; consistent with a higher nucleation density induced by higher instantaneous deposited flux.

As can be seen from Figure 9, the microstructure of the films deposited onto $\mathrm{SrTiO}_{3}(100)$ differs greatly from that on silicon. In this case, although distinct crystallites are visible in 
some of the films, the films are also largely continuous, albeit with some clear boundaries and pits. The smoothest and most continuous film is shown in Figure 9(b) and corresponds to that deposited using $7.6 \mathrm{~J} \mathrm{~cm}^{-2}$ fluence. At the highest fluence, $11 \mathrm{~J} \mathrm{~cm}^{-2}$, the film structure has changed to be more reminiscent of that found on $\mathrm{Si}(100)$ with small distinct crystallites; this is consistent with the finding of higher roughness for this sample.

\section{Conclusion}

PLD has been used to produce $30 \mathrm{~nm}$ films of $\mathrm{WO}_{\mathrm{x}}$ on $\mathrm{Si}(100)$ and $\mathrm{SrTiO}_{3}(100)$ substrates. The films have no bulk contaminants that could be determined by XPS and the tungsten W $4 \mathrm{f}$ orbitals show a chemical shift consistent with $\mathrm{WO}_{3}$ but with a shoulder indicating the presence of a small fraction of $\mathrm{W}^{5+}$. XRR measurements give surface roughness of the order of 1-2 nm on $\mathrm{SrTiO}_{3}(100)$ substrates but much larger on $\mathrm{Si}(100)$. This is confirmed by FEGSEM images showing the films grown on the former to be smooth but on the latter to be granular.

XRD measurements show the films to possess an orientational texture: all the films are oriented with the [001], [010], [100] directions normal to the surface. The pole-plots indicate that the films on $\mathrm{Si}(100)$ are uniaxially textured but those on $\mathrm{SrTiO}_{3}(100)$ are biaxially textured. The precise nature of the texture is affected by the laser fluence used to deposit: on $\mathrm{SrTiO}_{3}(100)$ a fluences in the region of 5.3-7.6 $\mathrm{Jcm}^{-2}$ produce smooth, highly crystalline biaxially textured films, that are close to epitaxial texture. Higher fluence promotes [001] texture, whereas low fluence promotes the other two textures. Experiments using laser repetition rate indicate that the underlying mechanism for the texture change with fluence is the mean deposition rate, with higher deposition rates promoting [001] texture and lower rate allowing the [010] and [100] to form.

\section{Acknowledgements}

We would like to thank the staff of the Loughborough Materials Characterisation Centre including: Keith Yendall for assistance with the pole plots, grazing incidence X-ray reflectivity and scanning electron microscopy; Pat Cropper and Alistair Exworthy for the Xray photoelectron spectroscopy. Bryan Dennis and Phil Sutton provided technical support in the PLD lab and for the X-ray Diffraction

\section{References}

[1] Ponzoni A, Comini E, Ferroni M, Sberveglieri G 2005 Thin Solid Films 49081 
[2] Granquist C G, 1993 Applied Physics A 573

[3] Zheng H D, Ou J Z, Strano M S, Kaner R B, Mitchell A, Kalantar-Zadeh K 2011 Advanced Functional Materials 212175.

[4] Lethy K J, Pandya S, Beena D, Vinodkumar R, Sathe V, Pillai V P M 2009 Journal of Physics D-Applied Physics 42185407.

[5] Eason R 2006 Pulsed Laser Deposition of Thin Films: Applications-Led Growth of Functional Materials ed. R Eason (Wiley-Blackwell) 9.

[6] Fang G J, Liu Z L, Sun G C, Yao K L, 2001 Physica Status Solidi A-Applied Research 184129

[7] Fang G J, Liu Z L, Yao K L, 2001 Journal of Physics D-Applied Physics 342260

[8] Lethy K J, Beena D, Kumar R V, Pillai V P M, Ganesan V, Sathe V 2008 Applied Surface Science 2542369.

[9] Garg A, Leake J A, Barber Z H, 2000 Journal of Physics D-Applied Physics 331048.

[10] Hussain O M, Swapnasmitha A S, John J, Pinto R 2005 Applied Physics A-Materials Science \& Processing 811291.

[11] Plonczak P, Bieberle-Hütter A, Søgaard M, Ryll T, Martynczuk J, Hendriksen P V, Gauckler L J, 2011 Advanced Functional Materials 212764

[12] Filipescu M, Orlando S, Russo V, Lamperti A, Purice A, Moldovan A, Dinescu M, 2007 Applied Surface Science 2538258.

[13] Al-Busaidy M S, Kusmartseva O E, Crapper M D 2004 Applied Physics A-Materials Science \& Processing 791453.

[14] Dietsch R, Holz Th, Mai H, Meyer C-F, Scholz R, Wehner B 1998 Applied Surface Science 127-129 451.

[15] Kostis I, Michalas L., Vasilopoulou M, Konofaos, N, Papaionnou G, Iliadis A A, Kennou S, Giannakopoulos K. Papdimitropoulos G, Davazoglou D, 2012 Journal of Physics D: Applied Physics 45445101

[16] Singh R K, Bhattacharya D, Narayan J 1990 Applied Physics Letters 572022

[17] Bruker AXS GmbH, Karlsruhe, Germany

[18] Avantage Data System, Thermo Scientific, http://xpssimplified.com/knowledgebase.php..

[19] Yous B, Robin S, Donnadieu A, Dufour G, Maillot C, Roulet H, Senemaud C 1984 Materials Research Bulletin 191349.

[20] Colton R J, Guzman A M, Rabalais J W 1978 Journal of Applied Physics 49409

[21] Hollinger G, Duc T M 1976 Physical Review Letters 371564

[22] Houweling Z S, Geus J W, Schropp R E I 2013 Materials Chemistry and Physics 14089

[23] Hashimoto S, Tanaka A, Murata A, Sakurada T 2004 Surface Science 55622.

[24] Powder Diffraction File, Joint Committee on Power Diffraction Standards, ASTM, Philadelphia, PA, 2000, Card 83-0950

[25] Powder Diffraction File, Joint Committee on Power Diffraction Standards, ASTM, Philadelphia, PA, 2000, Card 71-0131

[26] Powder Diffraction File, Joint Committee on Power Diffraction Standards, ASTM, Philadelphia, PA, 2000, Card 36-0102

[27] Booth J, T. Ekström T, Iguchi S E, Tilley J D, 1982 Journal of Solid State Chemistry 41293.

[28] Wilmott P R, Herger R, Schlepütz C M, Martoccia D, Patterson B D 2006 Physical Review Letters 96176102 
[29] Geohegan D B 1992 Thin Solid Films 138145.

[30] Harilal S S, Bindhu C V, Tillack M S, Najmabadi F, Gaeris A C 2003 Journal of Applied Physics 932380

[31] Amoruso S, Toftmann B, Schou J 2004 Physical Review E 69056403

[32] Chae H, Park S M 1998 Applied Surface Science 127-129 304

[33] Chu S S, Grigoropoulos C P 2000 Journal of Heat Transfer 122771.

[34] Metev S 1994 Pulsed Laser Deposition of Thin Films ed. Chrisey D B and Hubler G K (John Wiley \& Sons, New York) 255.

[35] Zhang X F, Kung H H, Foltyn S R, Jia Q X, Peterson E J, Peterson D E 1999 Journal of Materials Research 141204.

[36] Foltyn S R, Peterson E J, Coulter J Y, Arendt P N, Jia Q X, Dowden P C, Maley M P, Wu X D, Peterson D E 1997 Journal of Materials Research 122941

[37] Park J M, Nakashima S, Sogawa M, Kanashima T, Okuyama M 2013 Ferroelectrics 4531. 


\section{Figure Captions}

Figure 1: Surface analysis of the 7.6 $\mathrm{Jcm}^{-2} \mathrm{WO}_{\mathrm{x}}$ film, (a) X-ray photoelectron spectroscopy survey scan of the film deposited onto $\mathrm{SrTiO}_{3}(100)$ and (b) grazing incidence X-ray reflectivity measurements of $\mathrm{WO}_{\mathrm{x}}$ thin films deposited onto $\mathrm{Si}(100)$ and $\mathrm{SrTiO}_{3}(100)$ substrates (the solid line is a computational fit). The inset to (a) shows detail of the $\mathrm{W} 4 \mathrm{f}$ emission peaks.

Figure 2: $\theta / 2 \theta$ X-ray diffraction scans for $30 \mathrm{~nm} \mathrm{WO}_{\mathrm{x}}$ films deposited on $\mathrm{Si}(100)$ substrates at different laser fluence values: (a) $5.3 \mathrm{~J} \mathrm{~cm}^{-2}$; (b) $7.6 \mathrm{~J} \mathrm{~cm}^{-2}$; (c) $10.1 \mathrm{~J} \mathrm{~cm}^{-2}$; (d) $12.4 \mathrm{~J} \mathrm{~cm}^{-2}$ and (e) $14.7 \mathrm{~J} \mathrm{~cm}^{-2}$. All films were deposited at a substrate temperature of $500^{\circ} \mathrm{C}$ with a constant $\mathrm{O}_{2}$ background pressure of $2.5 \times 10^{-2}$ mbar. The X-ray diffraction scan of the $\mathrm{WO}_{3}$ target used for deposition is included for comparison.

Figure 3: $\theta / 2 \theta$ X-ray diffraction scans for $30 \mathrm{~nm} \mathrm{WO}_{\mathrm{x}}$ films deposited on $\mathrm{SrTiO}_{3}(100)$ substrates at different laser fluence values: (a) $5.3 \mathrm{~J} \mathrm{~cm}^{-2}$; (b) $7.6 \mathrm{~J} \mathrm{~cm}^{-2}$; (c) $10.1 \mathrm{~J} \mathrm{~cm}^{-2}$; (d) $12.4 \mathrm{~J} \mathrm{~cm}^{-2}$ and (e) $14.7 \mathrm{~J} \mathrm{~cm}^{-2}$. All films were deposited at a substrate temperature of $500^{\circ} \mathrm{C}$ with a constant $\mathrm{O}_{2}$ background pressure of $2.5 \times 10^{-2} \mathrm{mbar}$. The X-ray diffraction scan of the $\mathrm{WO}_{3}$ target used for deposition is included for comparison.

Figure 4: Comparison of the $\theta / 2 \theta \mathrm{X}$-ray diffraction scans for $30 \mathrm{~nm} \mathrm{WO}$ films deposited on $\mathrm{SrTiO}_{3}(100)$ substrates using $10.1 \mathrm{~J} \mathrm{~cm}^{-2}$ : the upper curve used a laser repetition rate of $10 \mathrm{~Hz}$ and the lower $5 \mathrm{~Hz}$. Both films were deposited at a substrate temperature of $500^{\circ} \mathrm{C}$ with a constant $\mathrm{O}_{2}$ background pressure of $2.5 \times 10^{-2}$ mbar.

Figure 5: (220) pole figures for thin films of $\mathrm{WO}_{\mathrm{x}}$ deposited onto Si(100): (a) $5.3 \mathrm{~J} \mathrm{~cm}^{-2}$; (b) $7.6 \mathrm{~J} \mathrm{~cm}^{-2}$; (c) $10.1 \mathrm{~J} \mathrm{~cm}^{-2}$; (d) $12.4 \mathrm{~J} \mathrm{~cm}^{-2}$ and (e) $14.7 \mathrm{~J} \mathrm{~cm}^{-2}$. Pole figures were collected to a maximum value of $\chi=74^{\circ}$.

Figure 6: (220) pole figures for thin films of $\mathrm{WO}_{\mathrm{x}}$ deposited onto $\mathrm{SrTiO}_{3}(100)$ : (a) $5.3 \mathrm{~J} \mathrm{~cm}^{-2}$; (b) $7.6 \mathrm{~J} \mathrm{~cm}^{-2}$; (c) $10.1 \mathrm{~J} \mathrm{~cm}^{-2}$; (d) $12.4 \mathrm{~J} \mathrm{~cm}^{-2}$ and (e) $14.7 \mathrm{~J} \mathrm{~cm}^{-2}$. The substrate (110) pole figure is shown in (f) for comparison. Pole figures were collected to a maximum value of $\chi=$ $74^{\circ}$.

Figure 7: (112) pole figures for thin films of $\mathrm{WO}_{\mathrm{x}}$ deposited onto $\mathrm{SrTiO}_{3}(100)$ : (a) $5.3 \mathrm{~J} \mathrm{~cm}^{-2}$; (b) $7.6 \mathrm{~J} \mathrm{~cm}^{-2}$; (c) $10.1 \mathrm{~J} \mathrm{~cm}^{-2}$; (d) $12.4 \mathrm{~J} \mathrm{~cm}^{-2}$ and (e) $14.7 \mathrm{~J} \mathrm{~cm}^{-2}$. The substrate (112) pole 
figure is shown in (f) for comparison. Pole figures were collected to a maximum value of $\chi=$ $74^{\circ}$.

Figure 8: Scanning electron micrographs of $30 \mathrm{~nm} \mathrm{WO}_{\mathrm{x}}$ films deposited onto $\mathrm{Si}(100)$ substrates at fluence values of (a) $5.3 \mathrm{~J} \mathrm{~cm}^{-2}$; (b) $7.6 \mathrm{~J} \mathrm{~cm}^{-2}$; (c) $10.1 \mathrm{~J} \mathrm{~cm}^{-2}$; (d) $12.4 \mathrm{~J} \mathrm{~cm}^{-2}$ and (e) $14.7 \mathrm{~J} \mathrm{~cm}^{-2}$. The contrast has been altered from the collected data for additional clarity.

Figure 9: Scanning electron micrographs of $30 \mathrm{~nm} \mathrm{WO}$ films deposited on $\mathrm{SrTiO}_{3}(100)$ substrates at fluence values of (a) $5.3 \mathrm{~J} \mathrm{~cm}^{-2}$; (b) $7.6 \mathrm{~J} \mathrm{~cm}^{-2}$; (c) $10.1 \mathrm{~J} \mathrm{~cm}^{-2}$; (d) $12.4 \mathrm{~J} \mathrm{~cm}^{-2}$ and (e) $14.7 \mathrm{~J} \mathrm{~cm}^{-2}$. The contrast has Figure 8 been altered from the collected data for additional clarity. 
Figure 1

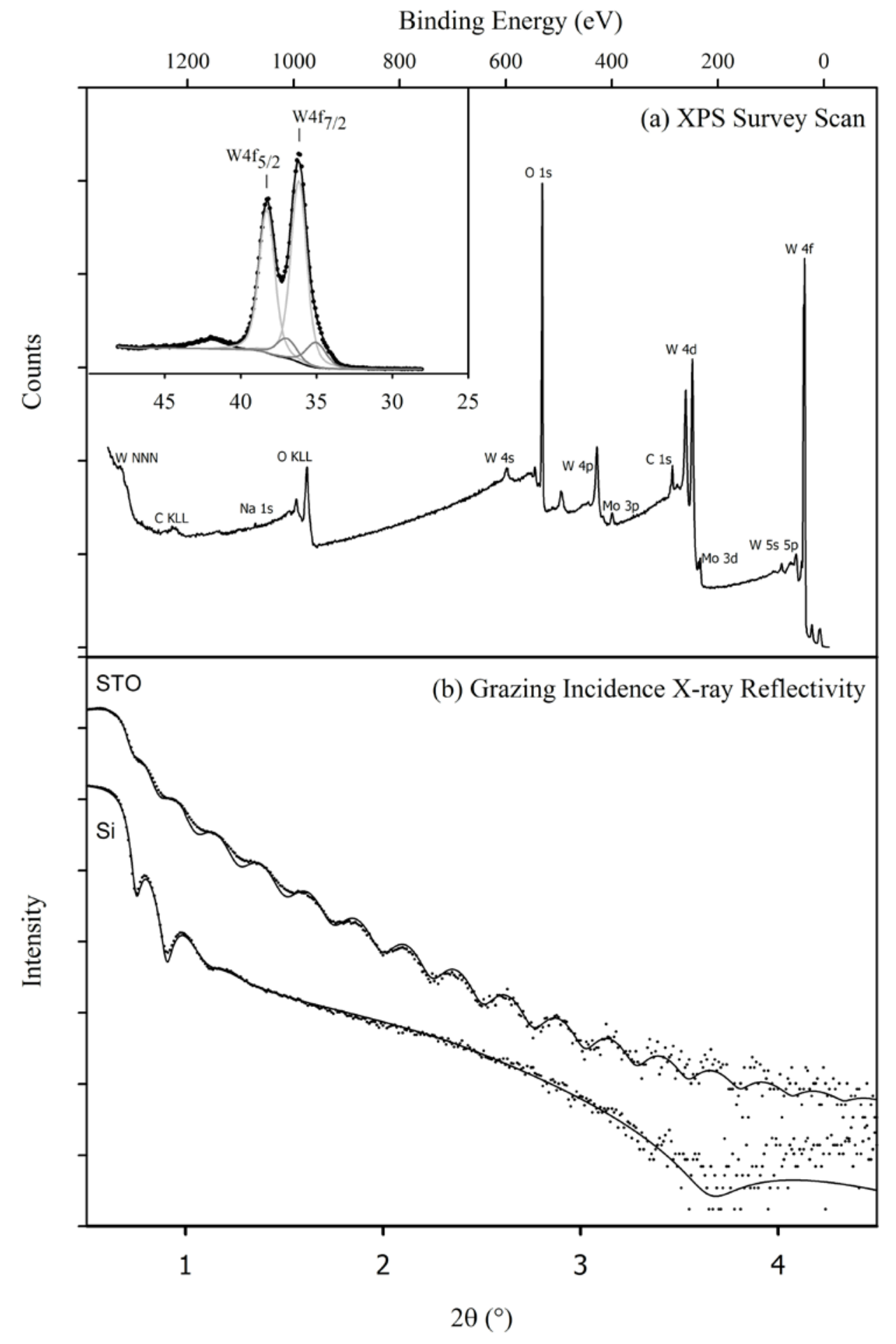


Figure 2

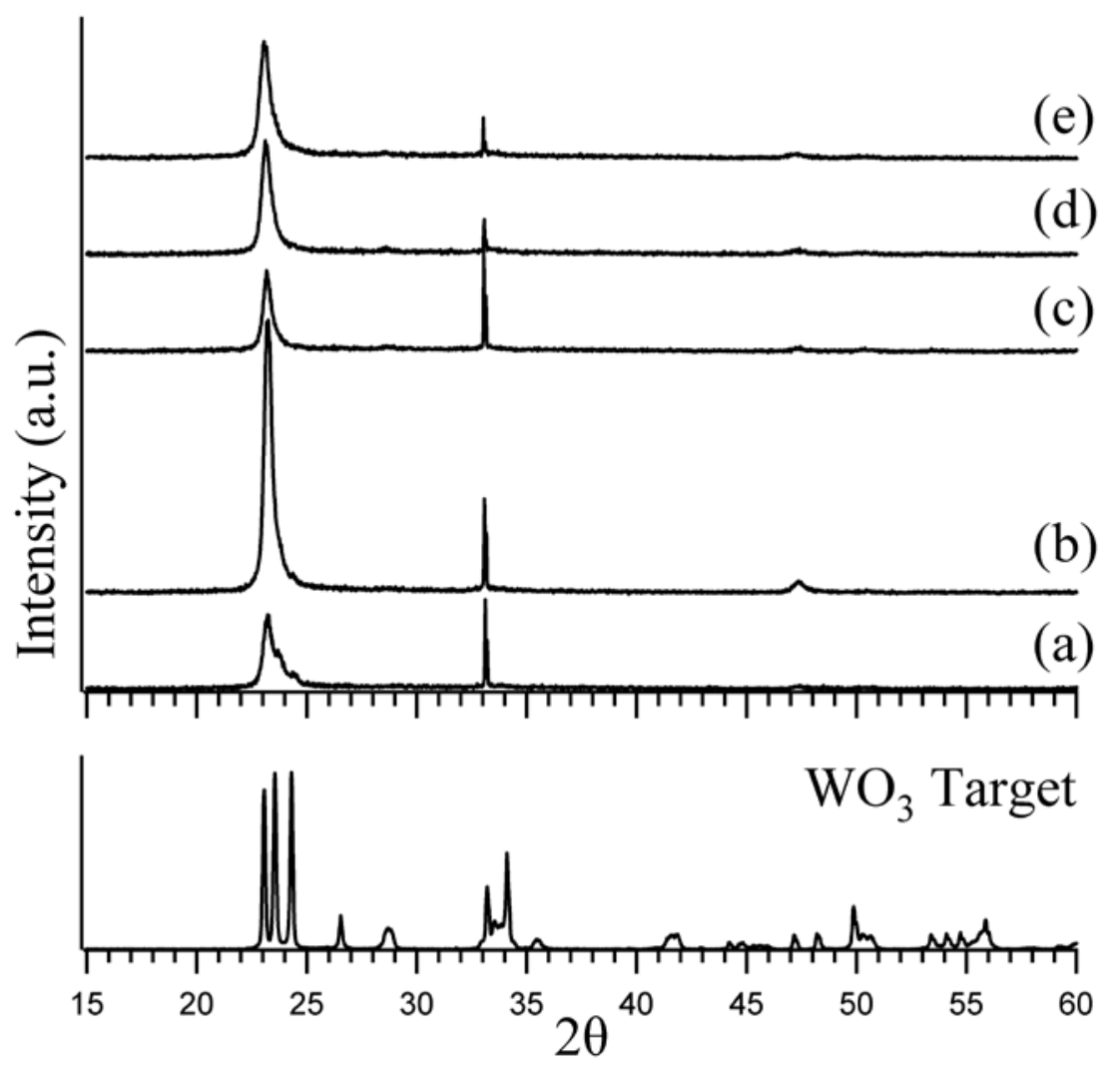


Figure 3

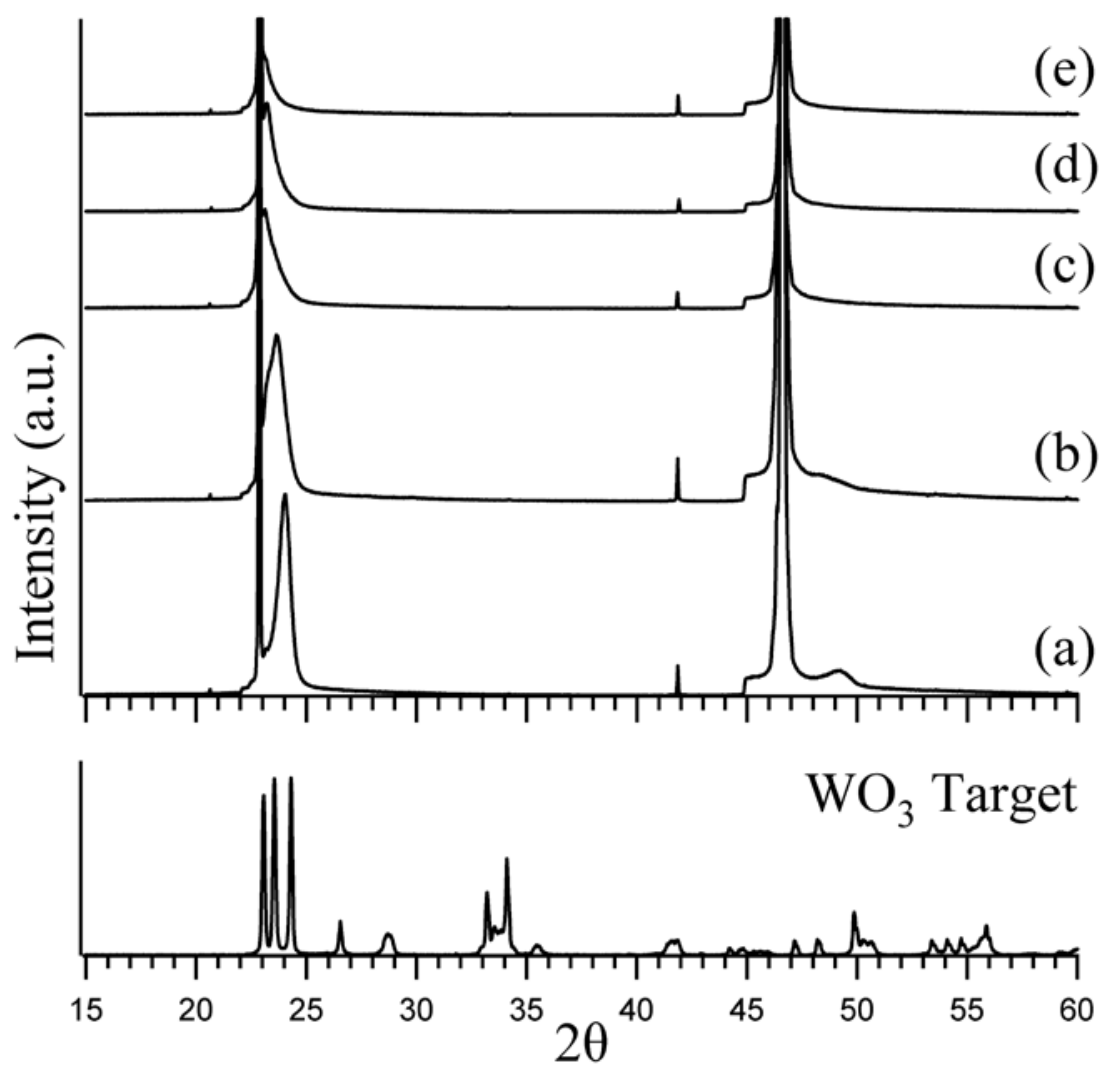


Figure 4

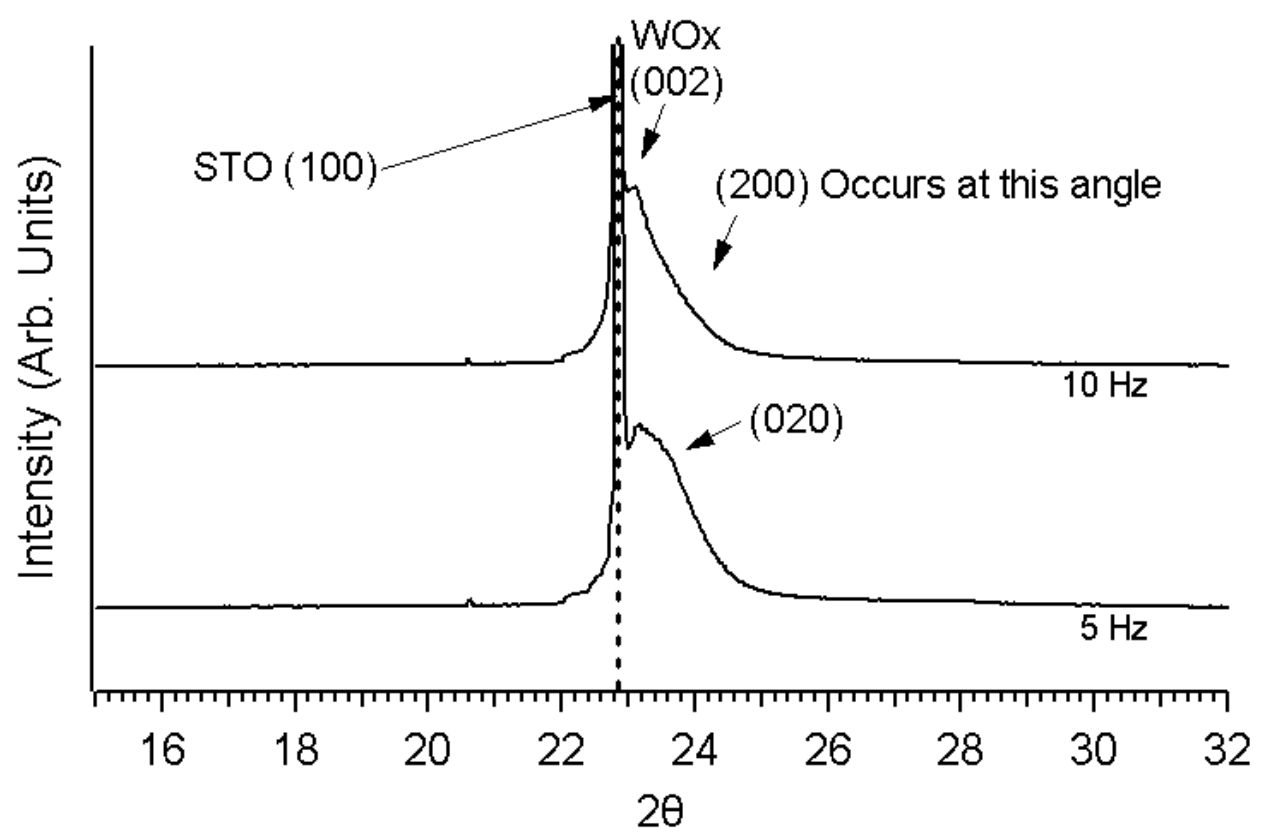


Figure 5

(a)

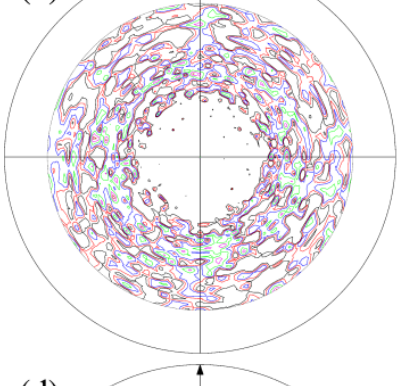

(d)

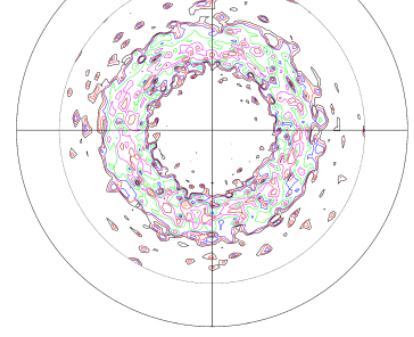

(b)

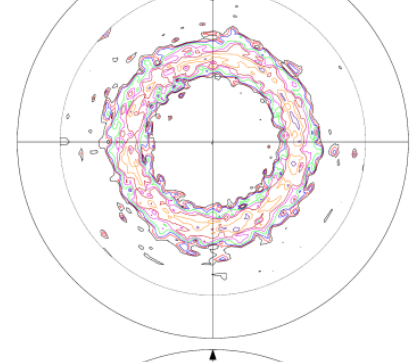

(e)

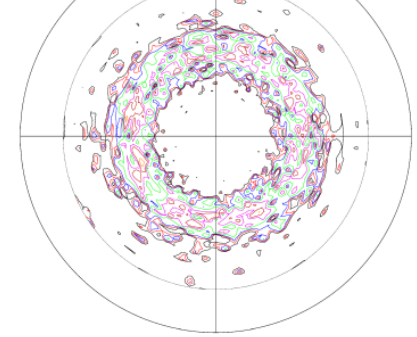

(c)

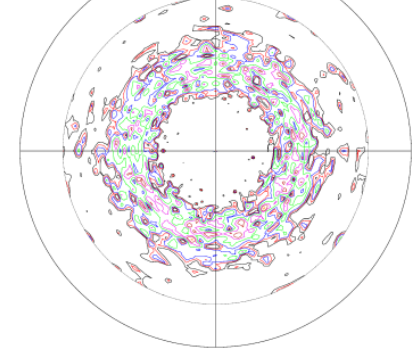


Figure 6

(a)

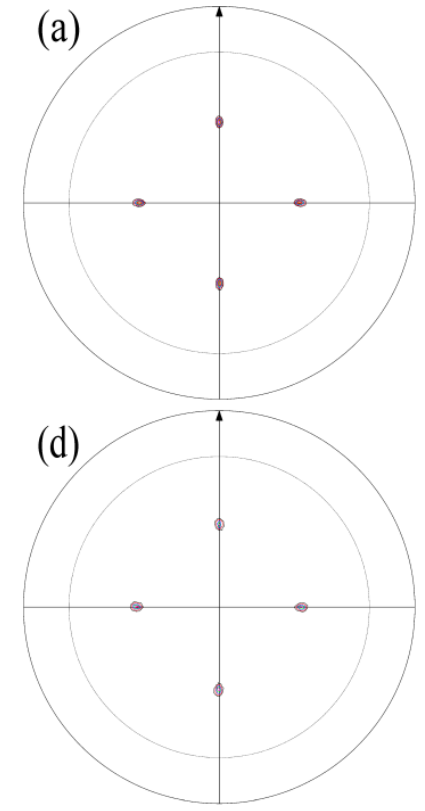

(b)

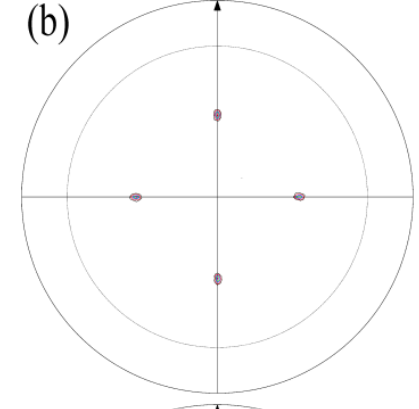

(e)

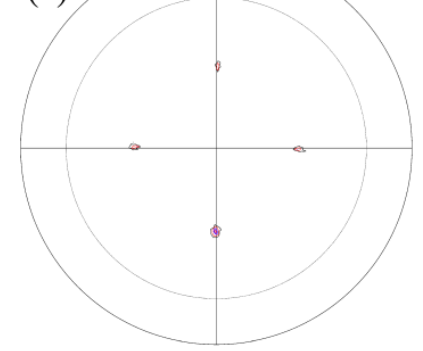

(c)

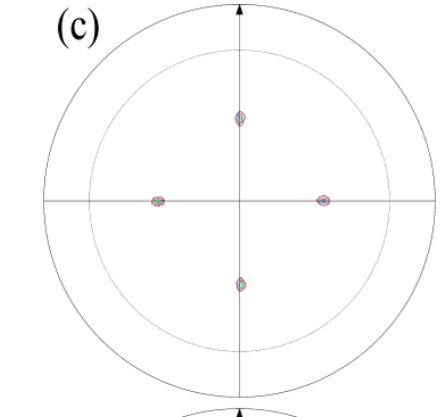

(f)

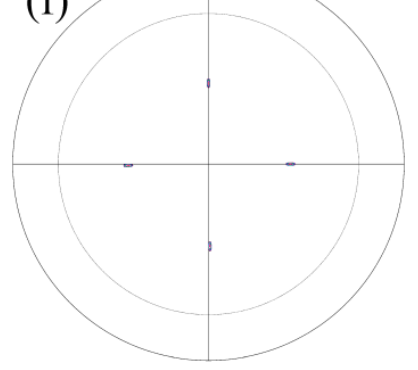


Figure 7

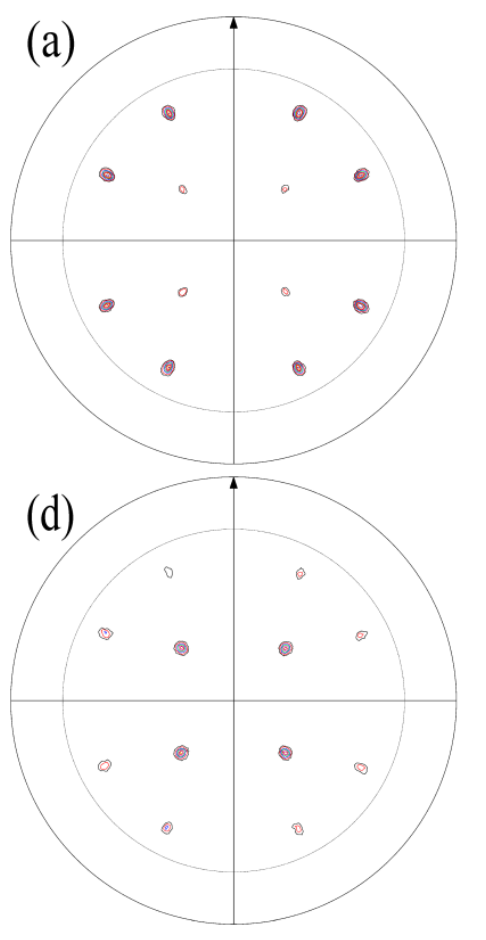

(b)

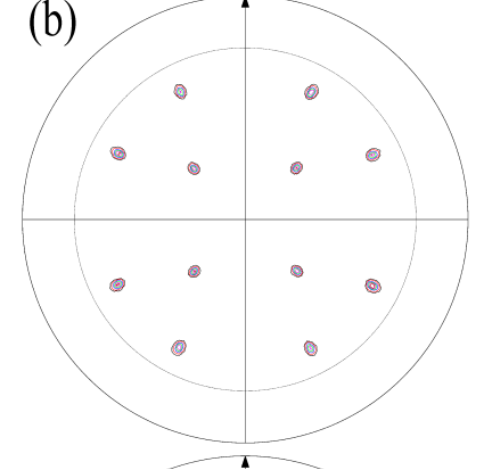

(e)

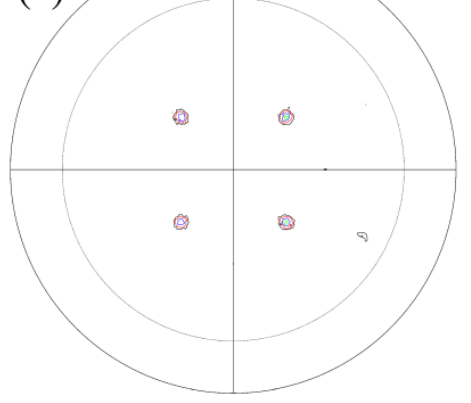

(c)

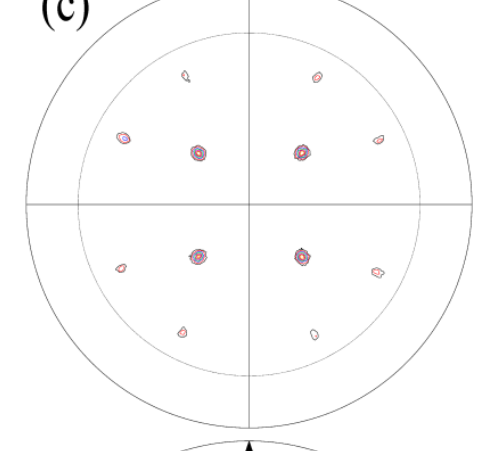

(f)

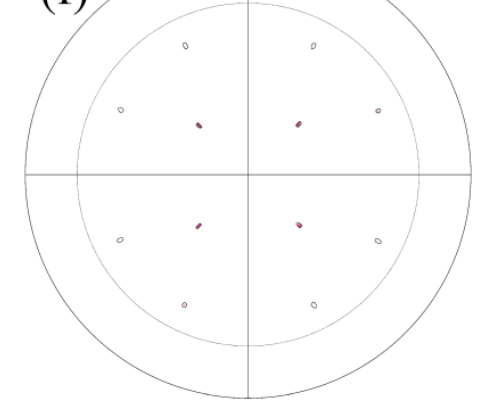


Figure 8

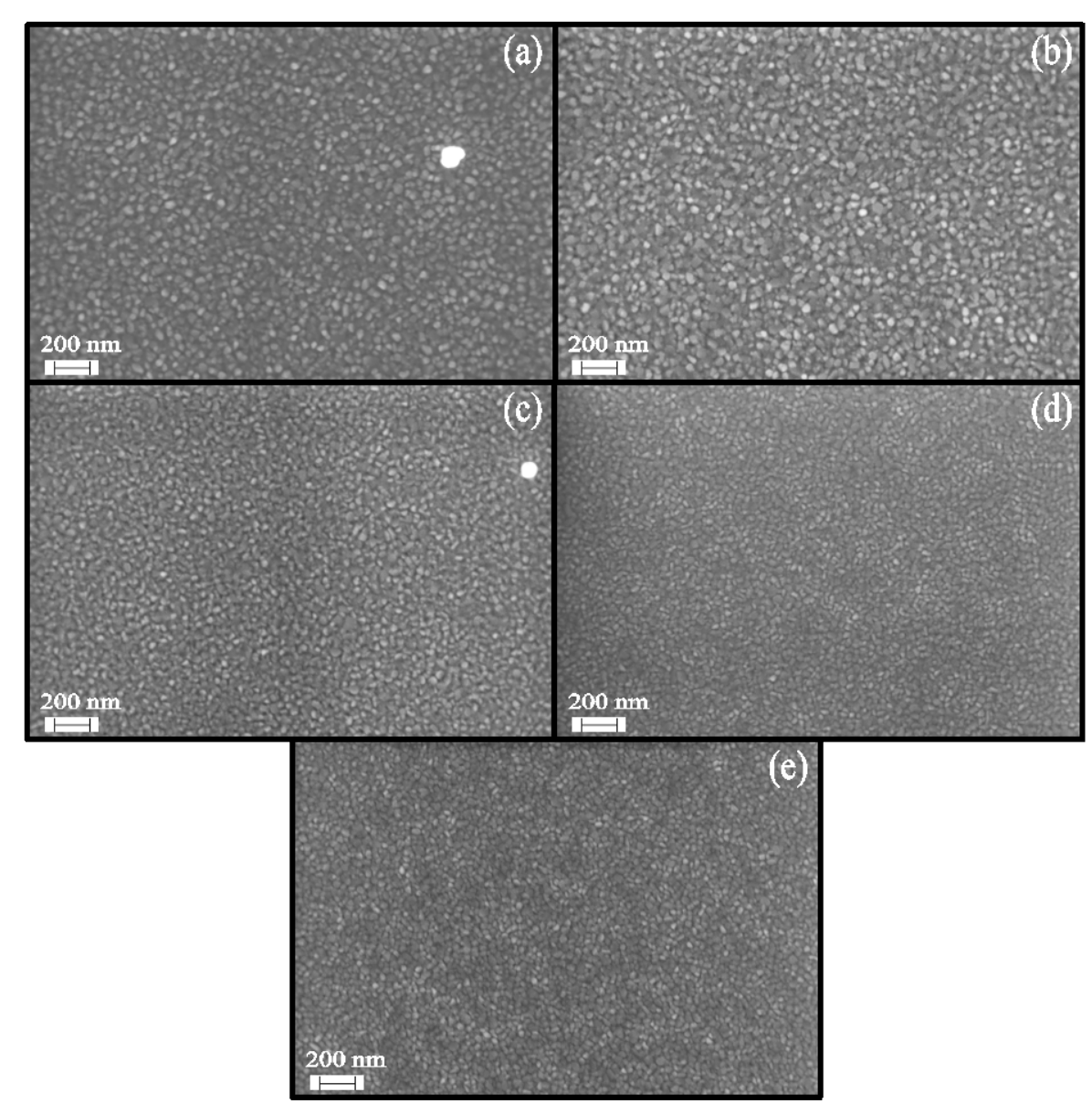


Figure 9

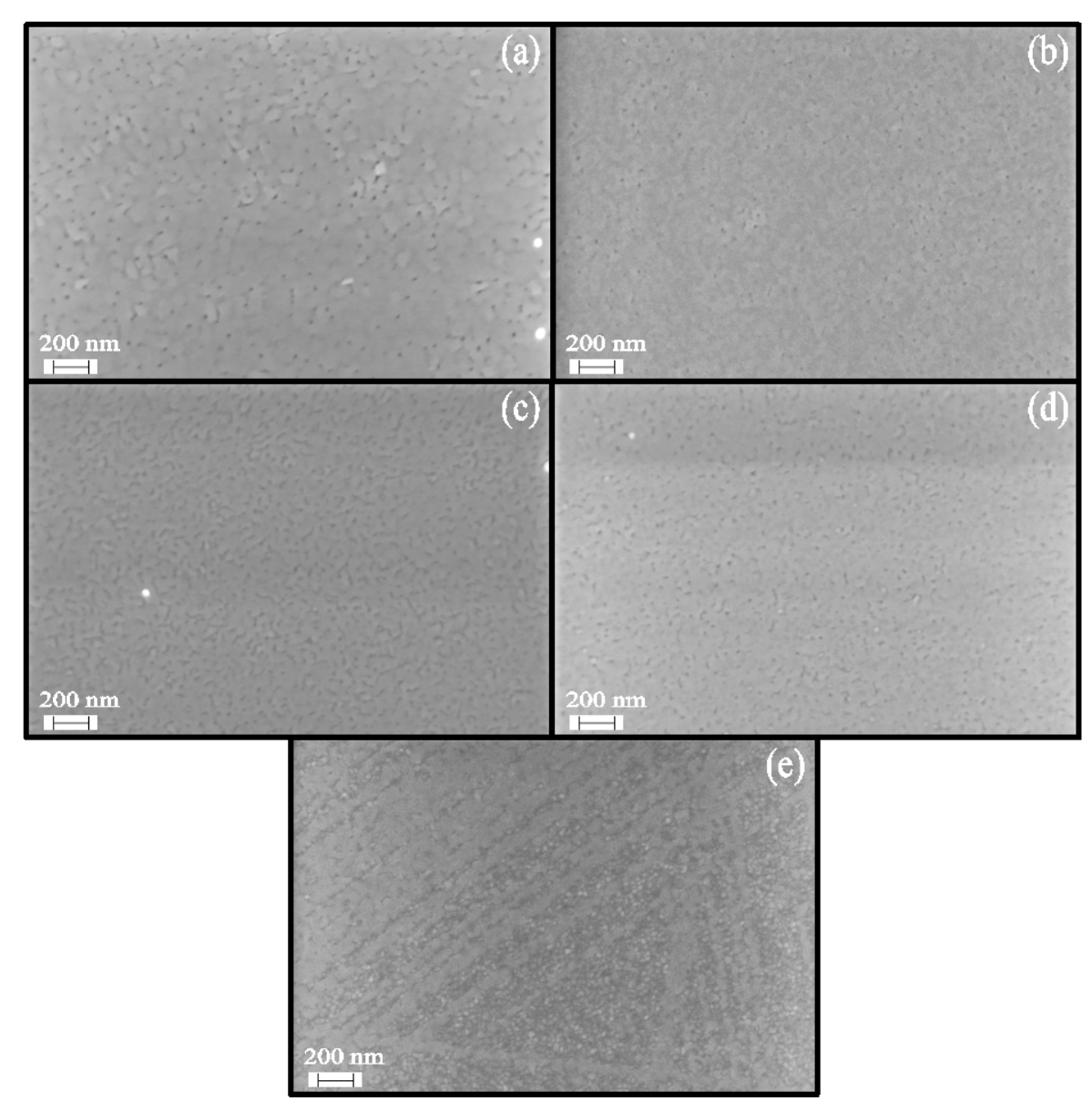

